\title{
PAPER PRESENTED AT INTERNATIONAL WORKSHOP ON INCREASING WHEAT YIELD POTENTIAL, CIMMYT, OBREGON, MEXICO, 20-24 MARCH 2006 Sink limitations to yield in wheat: how could it be reduced?
}

\author{
D. J. MIRALLES ${ }^{1,2 *}$ AND G. A. SLAFER ${ }^{3}$ \\ ${ }^{1}$ Catedra de Cerealicultura, Dto. Producción Vegetal, Facultad de Agronomia Universidad de Buenos Aires, \\ Av San Martin 4453 (C1417 DSE) Buenos Aires, Argentina \\ ${ }^{2}$ CONICET (Consejo Nacional de Investigaciones Cientificas y Tecnicas) Av. Rivadavia 1917 (C1033 AAJ), \\ Ciudad de Buenos Aires, Argentina \\ ${ }^{3}$ Research Professor of ICREA (Catalonian Institution for Research and Advanced Studies) at the Department of \\ Crop and Forest Sciences, University of Lleida, Centre Udl-IRTA, Av. Rovira Roure 191, 25198, Lleida, Spain
}

(Revised MS received 27 November 2006; First published online 13 February 2007)

\begin{abstract}
SUMMARY
Further genetic gains in wheat yield are required to match expected increases in demand. This may require the identification of physiological attributes able to produce such improvement, as well as the genetic bases controlling those traits in order to facilitate their manipulation. In the present paper, a theoretical framework of source and sink limitation to wheat yield is presented and the fine-tuning of crop development as an alternative for increasing yield potential is discussed. Following a top-down approach, most crop physiologists have agreed that the main attribute explaining past genetic gains in yield was harvest index (HI). By virtue of previous success, no further gains may be expected in HI and an alternative must be found. Using a bottom-up approach, the present paper firstly provides evidence on the generalized sink-limited condition of grain growth, determining that for further increases in yield potential, sink strength during grain filling has to be increased. The focus should be on further increasing grain number per $\mathrm{m}^{2}$, through fine-tuning pre-anthesis developmental patterns. The phase of rapid spike growth period (RSGP) is critical for grain number determination and increasing spike growth during pre-anthesis would result in an increased number of grains. This might be achieved by lengthening the duration of the phase (though without altering flowering time), as there is genotypic variation in the proportion of pre-anthesis time elapsed either before or after the onset of the stem elongation phase. Photoperiod sensitivity during RSGP could be then used as a genetic tool to further increase grain number, since slower development results in smoother floret development and more floret primordia achieve the fertile floret stage, able to produce a grain. Far less progress has been achieved on the genetic control of this attribute. None of the well-known major Ppd alleles seems to be consistently responsible for RSGP sensitivity. Alternatives for identifying the genetic factors responsible for this sensitivity (e.g. quantitative trait locus (QTL) identification in mapping populations) are being considered.
\end{abstract}

\section{SHOULD WE BE CONCERNED ABOUT WHEAT YIELD?}

During the 20th century, wheat production has been increased from 90 to 600 million tons due to increases

\footnotetext{
* To whom all correspondence should be addressed. Email: miralles@agro.uba.ar
}

in both harvested area and grain yield (Slafer et al. 1994). The most important expansion of harvested area occurred during the first half of the 20th century, reaching values of $c$. 200 million ha. Therefore, the increase in world wheat production from the beginning of the 1900 s to the 1950 s was due almost completely to increases in harvested area, while average 

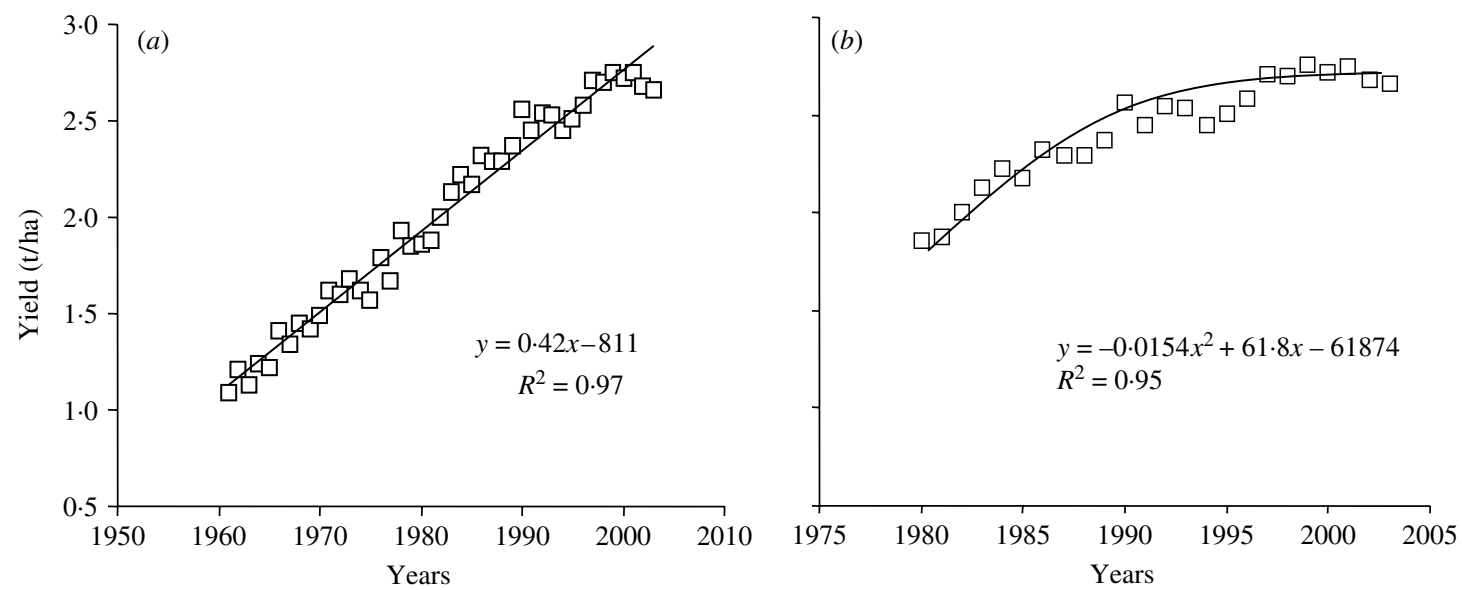

Fig. 1. Trends in worldwide wheat yields. A general trend from 1960 to 2004 (a) and a highlighted detail for the last 25 years (b). Solid lines correspond to a linear $(a)$ and curvilinear $(b)$ regression. Source of raw data: www.fao.gov.

yield remained virtually invariable (Slafer et al. 1996). Conversely, from the early 1960s onwards, yield increased noticeably (at an average rate of $40 \mathrm{~kg} / \mathrm{ha} /$ year, increasing from $c .1 \cdot 0 \mathrm{t} / \mathrm{ha}$ in 1960 to $2.6 \mathrm{t} / \mathrm{ha}$ in 2005; Fig. 1a). This increase was responsible for all increases of worldwide wheat production (Slafer \& Satorre 1999). Looking at this broad picture, one might be optimistic regarding meeting future demands, as production was able to cope satisfactorily with the dramatic increase in demand associated with doubling of the world population in those 50 or so years.

However, a closer look at the average yields during the last few years may give cause for concern. The rate of yield increase corresponding to the last 25 years was $36 \mathrm{~kg} / \mathrm{ha} /$ year (i.e. $14 \%$ less than that registered during the whole period from 1960) and the trend becomes clearly curvilinear, suggesting that wheat yields might be levelling off (Fig. 1b). In addition, the lack of clear and consistent trends in maintaining the increase in yields during the last two decades at the pace that characterized the period from the 1960s to the 1990s seemed to reflect the actual situation in most wheat-growing countries rather than just a worldwide average (Calderini \& Slafer 1998). In the future, the introduction of large new growing areas for sustainable production seems unlikely (Evans 1998); therefore, to increase wheat production to the level required at least to match the expected population growth, there will be dependence almost entirely on the ability to achieve the higher rates of yield gains that characterized the green revolution period (Evans 1998; Slafer et al. 1996).

Alternatives for producing further genetic gains in yield may focus on reducing the gap between actual and potential yield, or in further increasing yield potential (as it seems that, disregarding the existence of a yield gap, there is a relationship between potential and actual yields; e.g. Evans 1993; Abeledo et al. 2003).

In relation to the first alternative, genetic factors conferring adaptation through phenological adjustment or tolerance and resistance to abiotic and biotic stress could be manipulated. For example, the potential yield of wheat in the south-eastern Pampas, South America, is around $8 \mathrm{t} / \mathrm{ha}$, while attainable yield ranges between $4 \cdot 6$ and $6 \cdot 6 \mathrm{t} / \mathrm{ha}$ and average yield from $3 \cdot 5$ to $5 \cdot 2 \mathrm{t}$ /ha (Calviño \& Sadras 2002). In this scenario, almost 0.70 of variation in yield, and the reason for the discrepancy between actual and potential yield, was caused by water deficit during the critical period (i.e. 30 days before and 10 days after flowering; Fischer 1985) and high grain filling temperature (Calviño \& Sadras 2002). Quantification and qualification of the discrepancies between actual, attainable and potential yield are important to improve productivity of farming systems.

The alternative for further increases in yield potential may require firstly the identification of physiological attributes able to produce such improvement, and secondly the genetic bases controlling those traits in order to facilitate the manipulation (Slafer 2003). The impact of past wheat breeding on traits responsible for the achieved increase in yield potential has been reported in several countries (Loss \& Siddique 1994; Slafer et al. 1994; Calderini et al. 1999). However, future genetic gains in yield potential probably will be harder to achieve than in the past. A proper integration of molecular, crop-physiological and breeding approaches will be necessary (Slafer 2003; Edmeades et al. 2004; Sinclair et al. 2004). The combination of physiological and genetic information will provide a more complete model of 
gene-to-phenotype relationships and genotype-byenvironment interactions (Edmeades et al. 2004).

In the present paper, after briefly reviewing the main physiological changes produced by past breeding, the theoretical framework of source and sink limitation to wheat yield will be presented. Promising crop-physiological traits for further increase in yield potential will be discussed, with special emphasis on fine-tuning crop development as an alternative way for increasing yield potential.

\section{BRIEF ACCOUNT OF PHYSIOLOGICAL CHANGES PRODUCED BY BREEDERS WHEN INCREASING WHEAT YIELD POTENTIAL}

Wheat yield improvement in the past was mainly the result of increases in the partitioning of biomass to grains. A major step towards promoting this partitioning was provided by the introgression of dwarfing (Rht) genes (although the trend had already been evident since the earliest decades of the 20th century; e.g. Calderini et al. 1999). However, the likelihood of further increasing biomass partitioning to grains, harvest index $(\mathrm{HI})$, is rather low for different reasons. Mainly, the partitioning levels of modern varieties is close to 0.50 (Calderini et al. 1999), probably reaching the ceiling values (R. B. Austin, personal communication). Indeed, different studies have demonstrated that there has been no relevant genetic progress in HI since the 1980s (Sayre et al. 1997; Reynolds et al. 1999). In addition, one of the main attributes behind the increased HI in the past has been plant height. The relationship between yield and height is parabolic, delimiting a range of height to optimize yield (between 0.7 and 1.0 m, Richards 1992; Miralles \& Slafer 1995; Flintham et al. 1997) and most modern cultivars already possess a plant height within this range. Regarding the higher partitioning levels of modern cultivars, it is possible to speculate that yield progress in the future could be associated with increases in above-ground biomass within the optimum plant height described above. In providing evidence of the actual likelihood of this suggestion, Shearman et al. (2005) showed that yield progress in the UK from the 1970s to the 1980s occurred due to increases in HI (covering the period of semidwarfing genes introduction in the UK), whereas biomass increases explained most of the yield progress from the 1980s to the 1990s. Thus, the recent genetic gains in yield in the UK appeared to be based on the combination of an enhanced crop growth rate during pre-anthesis period (by increases in radiation use efficiency, RUE) and larger source during grain filling (by increases in water soluble carbohydrates). Reynolds et al. (2005) suggested that RUE could be increased by increasing sink-strength (i.e. more grains per unit land area). It was shown that spring wheat lines containing alien chromatin, i.e. 7DL.7Ag translocation, increased yield and biomass compared with controls, due to increases in RUE during post-anthesis as a consequence of sink strength during grain filling (more grains were set per unit land area in lines possessing the translocation).

Thus, it seems clear that understanding the physiological changes responsible for past genetic gains in yield (a top-down approach) contributes more to understanding which attributes may not be useful in future breeding than to identifying prospective useful traits. To propose traits that might help breeding for further increases in yield potential a bottom-up approach may be required, but it should be borne in mind at all times that any trait discussed must be related putatively to crop yield under field conditions (Slafer 2003).

In this context, the question of whether wheat yield actually is limited by the sink or the source strengths, particularly in modern high-yielding cultivars, is discussed. This is a requirement in order to device alternative opportunities for further increasing yield potential (e.g. it may be meaningless to suggest improvement of resource use at a time when yield may be hardly limited by source strength).

\section{WHEN ARE SOURCES AND SINKS LIMITING YIELD?}

A large body of evidence has demonstrated that variations in yield are explained mostly by changes in grains per unit land area, not only due to environmental effects (Fischer 1993; Magrin et al. 1993) but also due to genetic gains in yield (e.g. Calderini et al. 1999 and papers quoted therein). Thus, a clear positive relationship between yield and grains $/ \mathrm{m}^{2}$ is frequently found in a wide range of conditions (Fig. 2a). This suggests that, while the relationship is mostly linear (or at least has a dominant linear component), wheat yield is limited mainly by sink-strength during grain filling; although, as the number of grains is increased, the relationship becomes curvilinear suggesting a sort of source-sink co-limitation during grain filling.

There is evidence of a negative relationship between average grain weight and grains per unit area (Slafer \& Andrade 1989, 1993; Miralles \& Slafer 1995), indicating that increases in the number of grains are partially offset by reductions in grain weight. However, competition among growing grains due to source-limited during grain filling may not necessarily be the cause of this negative relationship. The alternative, non-competitive hypothesis is that the reduction in grain weight is associated with an increased proportion of grains of lower potential size (and weight) generally placed in distal positions within the spikelets and/or in secondary tiller spikes (Miralles \& Slafer 1995; Acreche \& Slafer 2006). 


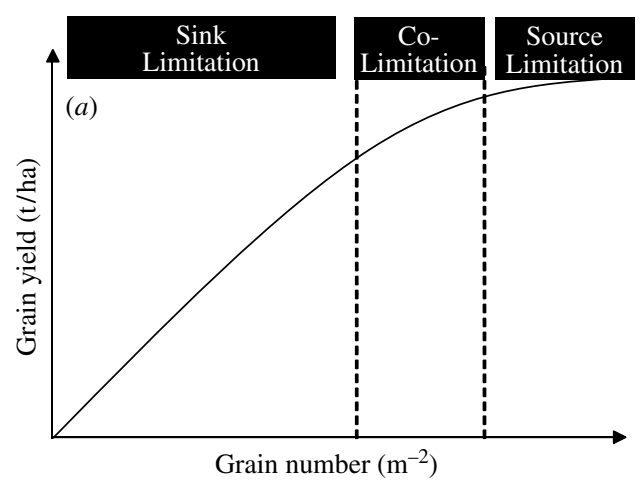

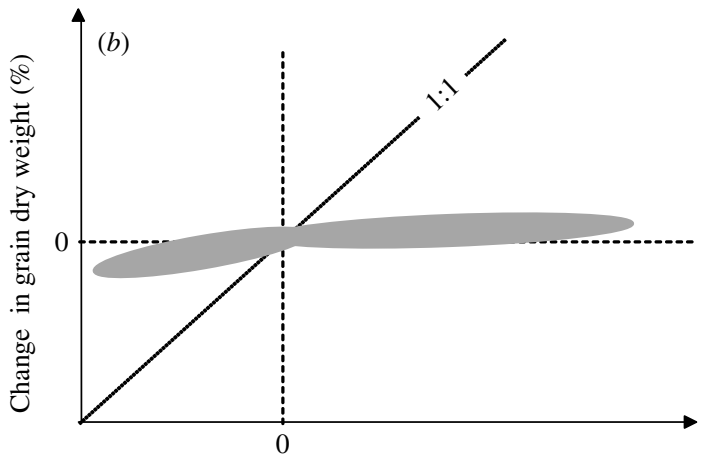

Change in assimilate avalilability per grain (\%)

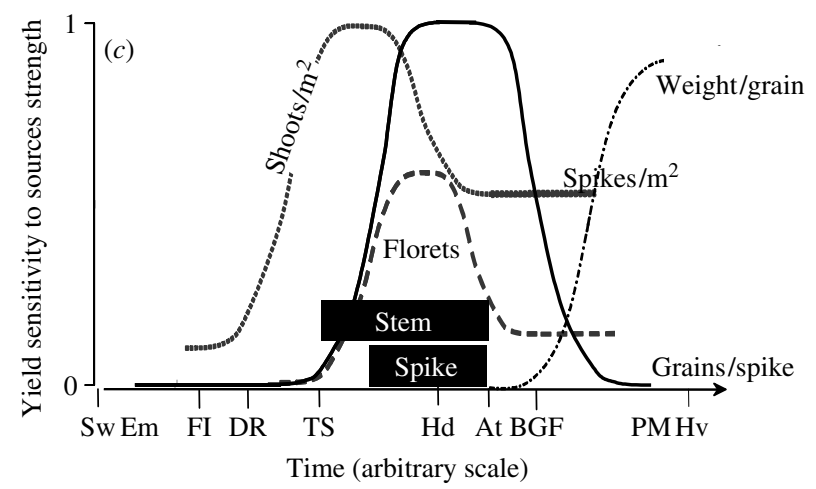

Fig. 2. Schematic relationship between yield and number of grains per unit area $(a)$ indicating when sink, source (or both simultaneously) are limiting yield potential in wheat. Panel $(b)$ shows changes in grain weight in response to variation in assimilate availability per grain during grain filling, based on Borras et al. (2004); while panel (c) exhibits a diagram of wheat development showing the yield sensitivity to source-strength at different stages throughout the growing season (main, thick line). This diagram also shows in the background other curves representing: the total number of shoots per $\mathrm{m}^{2}$ ending the curve with the number of spikes per $\mathrm{m}^{2}$ just before anthesis (dashed line); the total number of floret primordia per spike ending the curve with the number of those primordia developing to fertile florets (dotted line); grain weight (dashed and dotted line). Below the abscissa two boxes stand for the length of the period of stem and spike growth. Stages indicated in abscissas are sowing $(\mathrm{Sw})$, seedling emergence $(\mathrm{Em})$, floral initiation $(\mathrm{Fl})$, double ridge (DR), heading (Hd), anthesis (At), beginning of grain filling period (BGF), physiological maturity (PM) and harvest (Hv). Panel (c) is adapted from Slafer \& Savin (2006).

Under a wide range of agronomic conditions, the range of number of grains per unit area is generally within the region where the relationship between yield and grains per unit area is linear or only slightly curvilinear, supporting the suggestion that grain weight reductions associated with increased number of grains would be mostly non-competitive. This becomes clearer when experiments with source-sink manipulations during grain filling are analysed quantitatively.

For instance, Borras et al. (2004), based on Slafer \& Savin (1994), analysed a comprehensive database of c. 18 different experiments taken from studies where the source:sink ratio during grain filling was altered by different treatments. This quantitative approach demonstrated that wheat hardly shows any relevant level of source limitations for grain growth (see scheme of Fig. 2b), despite occasional reports of some 'statistically significant' effects.

Therefore, the critical traits to be considered for further increasing yield potential must be related to increases in sink size during grain filling, either by increasing the potential size of the grains or by further increasing grain number $/ \mathrm{m}^{2}$. The present paper focuses on the latter.

A large body of evidence has clearly established that grain number $/ \mathrm{m}^{2}$, although being generated during the whole period from sowing to immediately after anthesis (Slafer \& Rawson 1994), is extremely responsive to changes in growth/partitioning during only few weeks before anthesis (Fischer 1985). It is during this period when the spikes, where floret 


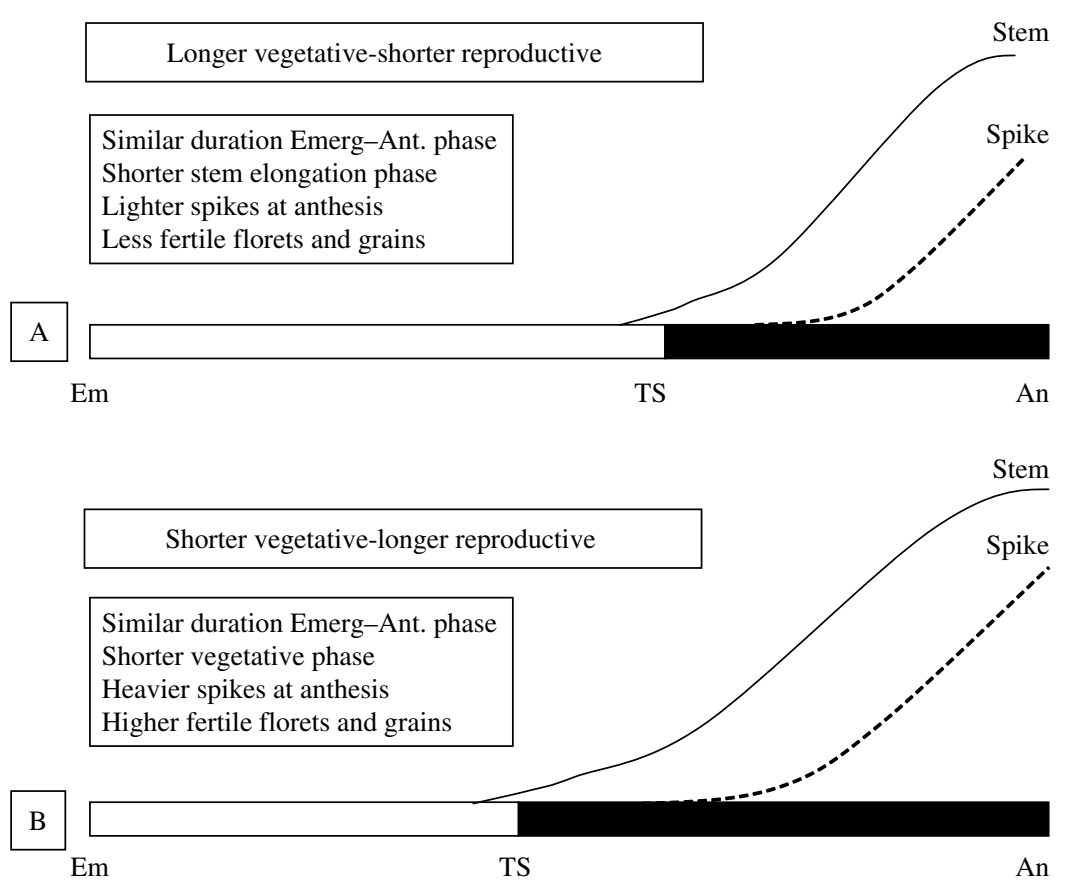

Fig. 3. Schematic figure representing the differences in two genotypes with different pre-anthesis duration of the phases.

development takes place, are growing at the fastest rate (Kirby 1988) and a clear relationship has been established between grain number $/ \mathrm{m}^{2}$ and spike dry weight at anthesis. This relationship was revealed initially from experiments based on manipulations of radiation or $\mathrm{CO}_{2}$ concentrations at different timings (Fischer 1985). Later studies have shown that genetic gains in yield also operate through increases in spike dry weight at anthesis, either by comparing old $v$. new cultivars (Siddique et al. 1989; Slafer \& Andrade 1989; Calderini et al. 1995; Sayre et al. 1997), by explaining effects of introgressing semidwarfism (Miralles \& Slafer 1995; Flintham et al. 1997), or other genetic means as alien translocation 7DL.7Ag (Reynolds et al. 2001, 2005; Miralles et al., in press). Thus, although crop yield is essentially a sourcedriven process (as the 'unit land area' on which basis yield is understood essentially represents a certain availability of resources in that area for a particular site $\times$ year $\times$ agronomic condition), it is only during a period of a few weeks before anthesis that the crop sensitivity to source-strength is critical for yield (Fig. 2c).

There are several alternative traits that might be used to increase RUE and radiation interception efficiency during this critical period (Slafer et al. 2001; Slafer 2003). The following section focuses on only one: development manipulation during the pre-anthesis phase as a main trait to reduce source limitation, through further increasing the number of grains per unit land area.

\section{MANIPULATING RELATIVE \\ DURATION OF PRE-ANTHESIS \\ PHASES AS A WAY FOR DIMINISHING SINK LIMITATION DURING GRAIN FILLING}

\section{Achieving increased spike dry weight at anthesis}

As described above, the phase of stem elongation, comprising terminal spikelet initiation (TSI) to anthesis (An) and within it the phase of rapid spike growth period (RSGP), has been identified by many authors as the most important phase for grain number and yield determination (Fischer 1983, 1985; Kirby 1988; Slafer et al. 1994; Miralles \& Slafer 1999). Since during this phase yield is strongly limited by source strength (that is why it is defined as the critical phase for yield determination, once the crop has been adequately established soon after sowing), any trait allowing more assimilates to be diverted to the growing spikes during that period would result in increases in spike dry weight at anthesis, in turn increasing number of grains per unit land area. Taking into account that further increases in partitioning seem unlikely (see above), it is necessary to explore possible alternatives related to increased growth, while maintaining high levels of biomass partitioning 

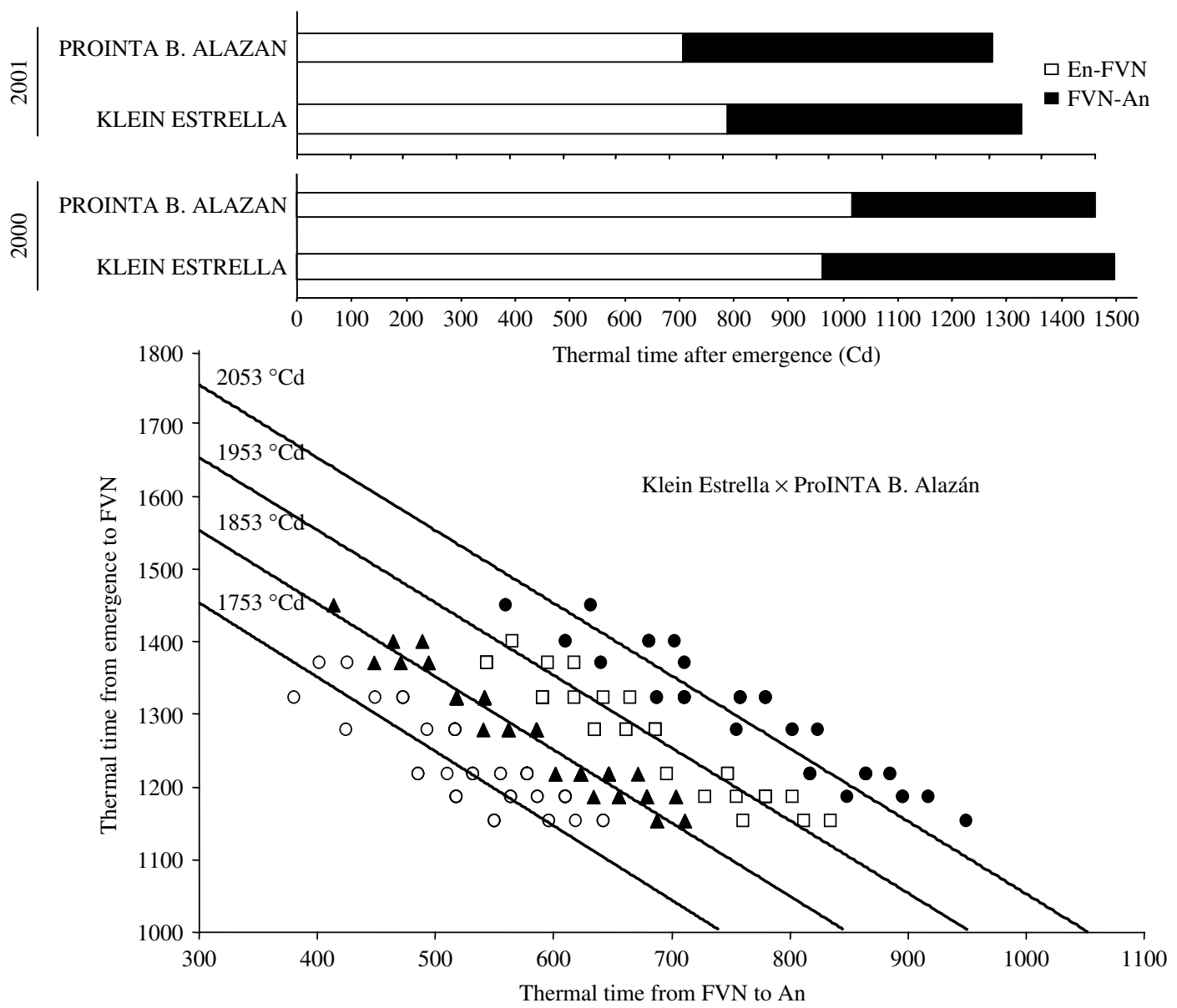

Fig. 4. (a) Duration of the pre-anthesis phases in two commercial argentine cultivars (ProINTA Alazan and Klein Estrella) with the same duration of the emergence-anthesis phase, as identified in earlier wide screenings (Whitechurch 2004). (b) Duration of stem elongation phase against of the duration of phase from seedling emergence to onset of stem elongation for all individuals of the F4 segregating population obtained from the cross between Klein Estrella (KE) and ProINTA Bonaerense Alazán (PA). The lines into the figure represent iso-thermal times from seedling emergence to anthesis. The groups were arbitrarily separated taking into account emergence to anthesis duration (Whitechurch et al., personal communication).

to growing spikes during this critical phase, as an avenue for improving the number of grains per unit area. There are two alternatives for achieving this hypothetical improvement: increasing crop growth rate during this particular phase (either increasing resource capture or resource use efficiency), or lengthening the duration of the phase maintaining rates of growth of the crop. The following section focuses on the latter.

\section{Photoperiod sensitivity during spike growth period}

The alternative avenue of lengthening the duration of stem elongation (or more specifically the RSGP) to keep increasing spike dry weight, and in turn number of grains, has been hypothesized (Slafer et al. 1996, 2001; Miralles et al. 2000; Slafer 2003). It is important to highlight that the main idea behind this hypothesis is that the flowering time should not be altered, as optimization of flowering time is an important objective for breeders and, consequently, modern high-yielding cultivars do already possess optimum timings of anthesis in most growing regions. To clarify the idea, a scheme showing the alternative durations of the preanthesis phase for two hypothetical genotypes with similar time to anthesis is given in Fig. 3, together with the representation of the outcome of this differential duration in terms of spike dry weight at anthesis if the hypothetical avenue proposed to further increase yield potential does work in reality. 


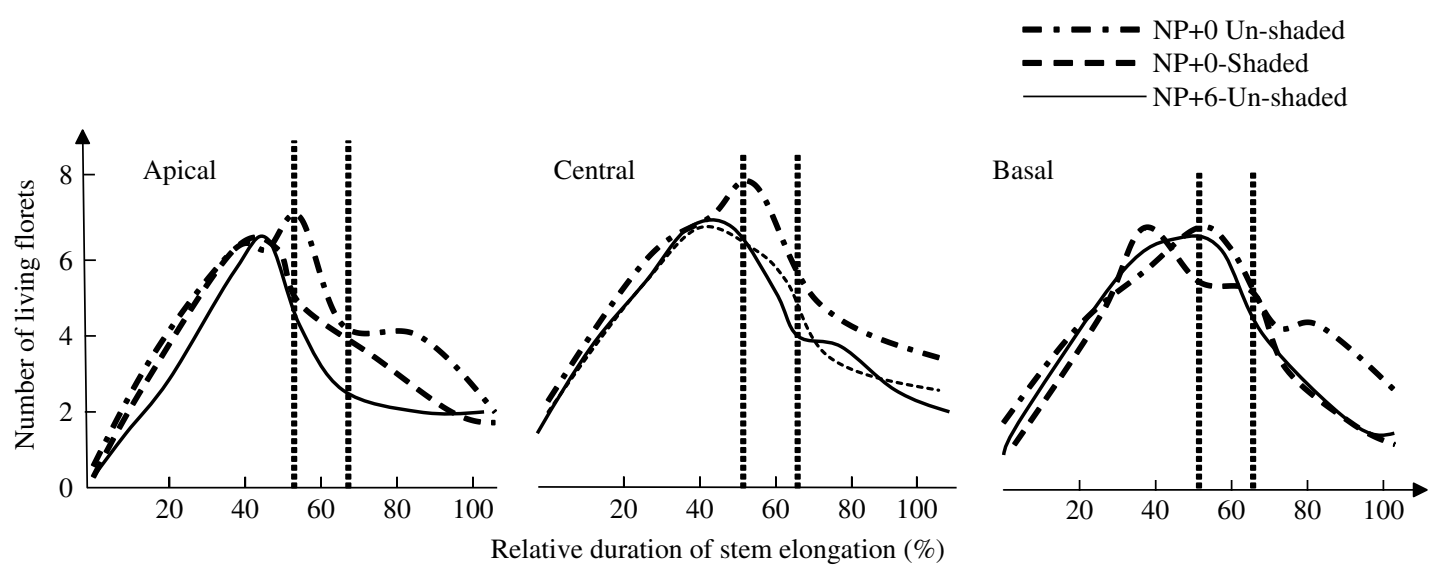

Fig. 5. Dynamics of the number of living florets during the stem elongation phase in apical, central and basal spikelets into the spike. Vertical tagged lines indicate the beginning of spike growth period for short (shaded and un-shaded) and long photoperiod. (Adapted from Gonzalez et al. 2005a.)

In relation to the hypothesis described above, three questions arise: (i) Is there variability in duration of RSGP within the same duration to anthesis in wheat? (ii) If so, would this variation be due - at least in part - to sensitivity of this phase to photoperiod? (iii) Might a longer duration of the RSGP really improve the fertility of the spike?

Regarding the first question, screening large numbers of cultivars for detailed developmental patterns has proved the existence of such variation (Slafer 2003). More interestingly, there are on-going studies attempting to establish the heritability of the length of the RSGP. Five pairs of commercial cultivars with the same time to anthesis but differing in the length of the stem elongation phase were selected as parental lines (see Fig. 4).

F4-segregating populations derived from crosses between these parental genotypes, obtaining recombinant inbred lines (RILs), showed important variation in time to anthesis. Dividing the population arbitrarily into four groups, important variation in the duration of the phases composing time to anthesis was found within each particular group (Fig. 4b). These RILs would be analysed further into two groups of lines with similar duration to flowering but contrasting partitioning of that developmental time in phases occurring either before or after the onset of stem elongation, determining whether yield and RUE in these populations are genetically linked with the duration of the spike growth period. Finally, these RILs would allow the identification of potential genetic factors likely to be associated with developmental patterns promoting the longer duration of the spike growth period without altering flowering time.

Regarding the second question, previous studies manipulating the photoperiod during the stem elongation phase carried out under controlled (Miralles
\& Richards 2000) and field conditions (Whitechurch \& Slafer 2002; Gonzalez et al. 2003a) demonstrated that the RSGP was sensitive to actual photoperiod, independently of the photoperiods to which the plants were exposed to before the onset of stem elongation. Therefore, photoperiod sensitivity during RSGP could be an avenue for elongating that phase to improve spike dry weight at anthesis and increase spike fertility (Slafer et al. 2001).

In relation to the last point associated with the speculation that increasing duration of the RSGP would result in higher spike dry weight at anthesis which is positively related to the number of grains per spike, different evidence appears to support this hypothesis (Miralles et al. 2000; Gonzalez et al. $2003 a, b$; Gonzalez et al. 2005a). In those studies, the number of fertile florets increased in a similar fashion to the spike dry weight, resulting in a higher number of grains. The maintenance of the close relationship between grain number and spike dry weight at anthesis when the duration of the RSGP was lengthened suggests that grain number increases due to shorter photoperiods were mediated by assimilates supply to the growing spikes. However, it could not be established clearly whether the photoperiod effects on the fate of floret primordia during the RSGP to reach the stage of fertile floret at anthesis was mediated by assimilate allocation to the spike (Gonzalez et al. $2003 \mathrm{~b}$ ). A study combining shading and photoperiod extensions, both during the RSGP only, was conducted recently to elucidate the possible interaction between possible direct photoperiod effects and assimilate availability mediated effects on the fate of floret primordial (Gonzalez et al. 2005a). It was shown that most photoperiod effects on the number of fertile florets, and grains, were mediated by assimilates supply to the growing spike (Fig. 5). 


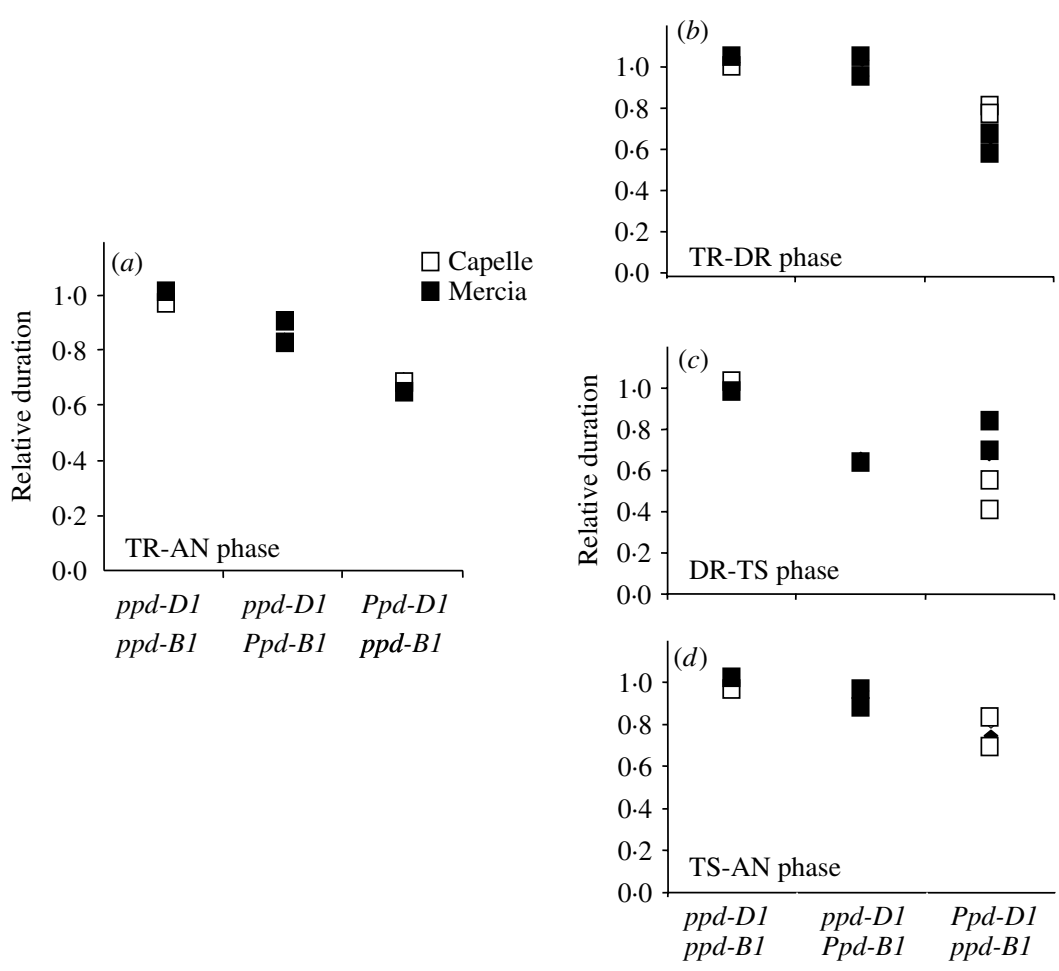

Fig. 6. Time to anthesis and duration of different pre-anthesis phases under natural photoperiod for Mercia (isogenic lines) and Capelle Deprez (recombinant lines). Figure was built from data of Table 4 in Gonzalez et al. (2005 b).

This is relevant as the practical outcome of this hypothetical avenue to increase yield potential would be to change photoperiod sensitivity during stem elongation and direct effects of photoperiod on the fate of florets would be physiologically exciting but agronomically unrewarding. A comprehensive study of the mechanisms involved in the fate of floret primordia, when stem elongation phase was modified, demonstrated that survival of florets positioned in the middle of the spikelet (mostly florets from the 3rd to 5th position within the spikelet) may be improved by increasing assimilate allocation to the spike (Gonzalez et al. 2005a).

\section{Genetic basis of sensitivity to photoperiod during spike growth period}

If confirmed for a wider range of genotypes and environmental backgrounds than those explored in the present studies, the evidence described above would demonstrate that changing the length of the RSGP, or more generally the stem elongation phase, by increasing photoperiod sensitivity during the RSGP (independently of photoperiod sensitivity in previous phases) would become an alternative, provided that an understanding of the genetic basis is reached. Understanding of the genetic control underlying the photoperiod sensitivity of different pre-flowering subphases must then be improved (much of what is known of photoperiod sensitivity has been produced considering the whole period from seedling emergence to anthesis as a single phase).

Photoperiod response in wheat is determined by a series of homologous loci $P p d-D 1$ (formerly $P p d 1$ ), $P p d-B 1$ (Ppd2) and Ppd-A1 (Ppd 3), located on the group 2 chromosomes: 2D, 2B and 2A, respectively (Welsh et al. 1973; Law et al. 1978; Scarth \& Law 1983). Although there are studies available on the impact of these genes on time to heading or anthesis and on yield and its components, only a rather limited effort has been devoted to analyse their effects on the duration of different pre-anthesis phases (Whitechurch \& Slafer 2001, 2002; Foulkes et al. 2004). Not only were the efforts limited but also the achieved results were conflicting (Gonzalez et al. $2005 \mathrm{~b}$ ). To illustrate the issue, using Mercia isogenic lines and Cappelle Deprez recombinant lines, and manipulating photoperiod in the field, Gonzalez et al. (2005b) recently observed that $P p d-D 1$ provided sensitivity to photoperiod during the pre-anthesis phase, 
while $p p d-B 1$ produced sensitivity only during the early reproductive phase (from seedling emergence to TSI). Whenever $P p d-D 1$ was present, a direct response to photoperiod during the stem elongation phase, including RSGP, was observed independently of the allelic form of $P p d-B 1$ (Fig. 6).

Despite no allele being particularly linked with photoperiod sensitivity during the RSGP, the results of Gonzalez et al. (2005b) reinforce the idea that photoperiod sensitivity of individual pre-anthesis phases may be independent of each other. New alleles and more genetic backgrounds should be tested to determine the fine-tuning of pre-anthesis development. Additionally, the thermo-photoperiodic models for different Ppd genes should be built for establishing whether the differences in duration of the phases is associated with changes in photoperiod sensitivity and/or in intrinsic earliness. Studies in this direction are being conducted.

One of the reasons for our rudimentary and rather poor understanding of the genetic control of the duration of the RSGP may be that only the effect of the well-established Ppd alleles have been studied. However, only a few of the major genes for photoperiod sensitivity are known, while many others are expected to exist (Snape et al. 2001). Therefore the understanding of the fine genetic control of duration of particular phases during pre-anthesis may require initially the clear identification of the other Ppd genes that are supposed to exist but have not been identified yet in wheat (Snape et al. 2001). Alternatively, attempts may be made to try to identify, within a mapping population, whether developmental patterns defining different partitioning of the time to anthesis into phases occurring before or after the onset of stem elongation. So far, this kind of work has been carried out in barley mapping populations and the first results were rather optimistic with a major QTL for duration of seedling emergence-onset of stem elongation in chromosome 1 and a totally independent QTL (on chromosome 2) controlling duration of the stem elongation phase (Marti, personal communication). The same kind of study was then conducted with a different mapping population and under a wide range of environmental conditions, and although the results do not coincide totally, some independent genetic control of both phases seem to emerge (though far more analysis and experimentation, particularly with a wheat mapping population, has to be conducted before trustworthy conclusions may be reached).

\section{REFERENCES}

Abeledo, L. G., Calderini, D. F. \& Slafer, G. A. (2003). Genetic improvement of barley yield potential and its physiological determinants in Argentina (1944-1998). Euphytica 130, 325-334.

Acreche, M. M. \& Slafer, G. A. (2006). Grain weight response to increases in number of grains in wheat in a Mediterranean area. Field Crops Research 98, 52-59.

Borras, L., Slafer, G. A. \& Otegui, M. E. (2004). Seed dry weight response to source-sink manipulations in wheat, maize and soybean: a quantitative reappraisal. Field Crops Research 86, 131-146.

Calderini, D. F. \& Slafer, G. A. (1998). Changes in yield and yield stability in wheat during the 20th century. Field Crops Research 57, 335-347.

Calderini, D. F., Dreccer, M. F. \& Slafer, G. A. (1995). Genetic improvement in wheat yield and associated traits. A re-examination of previous results and latest trends. Plant Breeding 114, 108-112.

Calderini, D. F., Reynolds, M. P. \& Slafer, G. A. (1999). Genetic gains in wheat yield and main physiological changes associated with them during the 20th century. In Wheat: Ecology and Physiology of Yield Determination (Eds E. H. Satorre \& G. A. Slafer), pp. 351-377. New York: Food Product Press.

Calviño, P. \& Sadras, V. (2002). On-farm assessment of constraints to wheat yield in the south-eastern Pampas. Field Crops Research 74, 1-11.

Edmeades, G. O., McMaster, G. S., White, J. W. \& Campos, H. (2004). Genomics and the physiologist: bridging the gap between genes and crop response. Field Crops Research 90, 5-18.

Evans, L. T. (1993). Crop Evolution, Adaptation and Yield. Cambridge, UK: Cambridge University Press.
Evans, L. T. (1998). Feeding the Ten Billion: Plants and Population Growth. Cambridge, UK: Cambridge University Press.

Fischer, R. A. (1983). Wheat. In Potential Productivity of Field Crops under Different Growth Conditions (Eds W. H. Smith and J. J. Banta), pp. 129-154. Los Baños, Philippines: IRRI.

Fischer, R. A. (1985). Number of kernels in wheat crops and the influence of solar radiation and temperature. Journal of Agricultural Science, Cambridge 105, 447-461.

FISCHER, R. A. (1993). Irrigated spring wheat and timing and amount of nitrogen fertilizer. II. Physiology of grain yield response. Field Crops Research 33, 57-80.

Flintham, J. E., Borner, A., Worland, A. J. \& Gale, M. D. (1997). Optimizing wheat grain yield: effects of Rht (gibberellin-insensitive) dwarfing genes. Journal of Agricultural Science, Cambridge 128, 11-25.

Foulkes, M. J., Sylvester-Bradley, R., Worland, A. J. \& SNAPE, J. W. (2004). Effects of a photoperiod-response gene Ppd-D1 on yield potential and drought resistance in UK winter wheat. Euphytica 135, 63-73.

Gonzalez, F. G., Slafer, G. A. \& Miralles, D. J. (2003a). Grain and floret number in response to photoperiod during stem elongation in fully and slightly vernalized wheats. Field Crops Research 81, 17-27.

Gonzalez, F. G., Slafer, G. A. \& Miralles, D. J. (2003b). Floret development and spike growth as affected by photoperiod during stem elongation in wheat. Field Crops Research 81, 29-38.

Gonzalez, F. G., Slafer, G. A. \& Miralles, D. J. (2005a). Photoperiod during stem elongation in wheat: is its impact on fertile floret and grain number determination 
similar to that of radiation? Functional Plant Biology 32, 181-188.

Gonzalez, F. G., Slafer, G. A. \& Miralles, D. J. $(2005 b)$. Pre-anthesis development and number of fertile florets in wheat as affected by photoperiod sensitivity genes Ppd-D1 and Ppd-B1. Euphytica 146, 253269.

KIRBy, E. J. M. (1988). Analysis of leaf, stem and ear growth in wheat from terminal spikelet stage to anthesis. Field Crops Research 18, 127-140.

Law, C. N., SutKa, J. \& Worland, A. J. (1978). A genetic study of daylength response in wheat. Heredity 41, 185191.

Loss, S. P. \& Siddique, K. H. M. (1994). Morphological and physiological traits associated with wheat yield increases in Mediterranean environments. Advances in Agronomy 52, 229-276.

Magrin, G. O., Hall, A. J., Baldy, C. \& Grondona, M. O. (1993). Spatial and interannual variations in the phototermal quotient: implications for the potential kernel number of wheat crops in Argentina. Agricultural and Forest Meteorology 67, 29-41.

Miralles, D. J. \& Richards, R. A. (2000). Responses of leaf and tiller emergence and primordium initiation in wheat and barley to interchanged photoperiod. Annals of Botany 85, 655-663.

Miralles, D. J. \& Slafer, G. A. (1995). Yield, biomass and yield components in dwarf, semidwarf and tall isogenic lines of spring wheat under recommended and late sowings dates. Plant Breeding 114, 392-396.

Miralles, D. J. \& Slafer, G. A. (1999). Wheat development In Wheat: Ecology and Physiology of Yield Determination (Eds E. H. Satorre \& G. A. Slafer), pp. 13-43. New York: Food Product Press.

Miralles, D. J., Richards, R. A. \& Slafer, G. A. (2000). Duration of stem elongation period influences the number of fertile florets in wheat and barley. Australian Journal of Plant Physiology 27, 931-940.

Miralles, D. J., Resnicoff, E. \& Carretero, R. (in press). Yield improvement associated with Lr19 translocation in wheat: which plant attributes are modified? In Scale \& Complexity in Plant Systems Research: Gene-Plant-Crop Relations (Eds J. H. J. Spiertz, P. C. Struik \& H. H. van Laar), pp. 169-176. Wageningen UR Frontis Series, Vol. 20 (Series Ed. R. J. Bogers). Dordrecht, The Netherlands: Springer. Available online at http://library.wur.nl/frontis/ gene-plant-crop/ (verified 5/12/06).

Reynolds, M. P., Sayre, K. D. \& Rajaram, S. (1999). Physiological and genetic changes of irrigated wheat in the post green revolution period and approaches for meeting projected global demand. Crop Science 39, 1611-1621.

Reynolds, M. P., Calderini, D. F., Condon, A. G. \& Rajaram, S. (2001). Physiological basis of yield gains in wheat associated with LR19 translocation from Agropyron elongatum. Euphytica 119, 137-141.

Reynolds, M. P., Pellegrineschi, A. \& Skovmand, B. (2005). Sink limitation to yield and biomass: a summary of some investigations in spring wheat. Annals of Applied Biology 146, 39-49.

Richards, R. A. (1992). The effect of dwarfing genes in spring wheat in dry environments I. Agronomic characteristics. Australian Journal of Agricultural Research 43, $517-522$.
Sayre, K. D., Rajaram, S. \& Fischer, R. A. (1997). Yield potential progress in short bread wheats in northwest Mexico. Crop Science 37, 36-42.

SCARTh, R. \& Law, C. N. (1983). The location of the photoperiod gene, Ppd 2 and an additional genetic factor for ear-emergence time on chromosome 2B of wheat. Heredity 51, 607-619.

Shearman, V. J., Sylvester-Bradley, R., Scott, R. K. \& Foulkes, M. J. (2005). Physiological processes associated with wheat yield progress in the UK. Crop Science 45, 175-185.

Siddique, K. H. M., Kirby, E. J. M. \& Perry, M. W. (1989). Ear:stem ratio in old and modern wheat varieties, relationship with improvement in number of grains per ear and yield. Field Crops Research 21, 59-78.

Sinclair, T. R., Purcell, L. C. \& Sneller, C. H. (2004). Crop transformation and the challenge to increase yield potential. Trends in Plant Science 9, 70-75.

Slafer, G. A. (2003). Genetic basis of yield as viewed from a crop physiologist's perspective. Annals of Applied Biology 142, 117-128.

Slafer, G. A. \& Andrade, F. H. (1989). Genetic improvement in bread wheat (Triticum aestivum) yield in Argentina. Field Crops Research 21, 289-296.

Slafer, G. A. \& Andrade, F. H. (1993). Physiological attributes related to the generation of grain yield in bread wheat cultivars released at different eras. Field Crops Research 31, 351-367.

Slafer, G. A. \& Rawson, H. M. (1994). Sensitivity of wheat phasic development to major environmental factors: a reexamination of some assumptions made by physiologists and modellers. Australian Journal of Plant Physiology 21, 393-426.

Slafer, G. A. \& Satorre, E. H. (1999). An introduction to the physiological-ecological analysis of wheat yield. In Wheat: Ecology and Physiology of Yield Determination (Eds E. H. Satorre \& G. A. Slafer), pp. 3-12. New York: Food Product Press.

Slafer, G. A. \& SAvin, R. (1994). Source-sink relationships and grain mass at different positions within the spike in wheat. Field Crops Research 37, 39-49.

Slafer, G. A. \& SAvin, R. (2006). Physiology of crop yield. In Encyclopedia of Plant and Crop Science (Ed. R. M. Goodman). New York: Marcel Dekker Inc. (in press).

Slafer, G. A., Satorre, E. H. \& Andrade, F. H. (1994). Increases in grain yield in bred wheat from breeding and associated physiological changes. In Genetic Improvement of Field Crops: Current Status and Development. (Ed. G. A. Slafer), pp. 1-68. New York: Marcel Dekker Inc.

Slafer, G. A., Calderini, D. F. \& Miralles, D. J. (1996). Yield components and compensation in wheat: opportunities for further increasing yield potential. In Increasing Yield Potential in Wheat: Breaking the Barriers (Eds M. P. Reynolds, S. Rajaram \& A. McNab), pp. 101-133. Mexico, DF: CIMMYT.

Slafer, G. A., Abeledo, L. G., Miralles, D. J., González, F. G. \& Whitechurch, E. M. (2001). Photoperiod sensitivity during stem elongation as an avenue to raise potential yield in wheat. Euphytica 119, 191-197.

Snape, J. W., Butterworth, K., Whitechurch, E. M. \& Worland, A. J. (2001). Waiting for the fine times: genetics of flowering time in wheat. Euphytica 119, 185-190. 
Welsh, J. R., Klein, D. L., Pirasteh, B. \& Richards, R. D. (1973). Genetic control of photoperiod response in wheat. In Proceedings of the 4th International Wheat Genetic Symposium (Eds E. R. Sears \& L. S. M. Sears), pp. 879-884. Columbia, Missouri, USA: University of Missouri Press.
Whitechurch, E. M. \& Slafer, G. A. (2001). Response to photoperiod before and after jointing in wheat substitution lines. Euphytica 118, 47-51.

Whitechurch, E. M. \& Slafer, G. A. (2002). Contrasting Ppd alleles in wheat: effects on sensitivity to photoperiod in different phases. Field Crops Research 73, 95-105. 